http://jmscr.igmpublication.org/home/ ISSN (e)-2347-176x ISSN (p) 2455-0450

crossref DOI: https://dx.doi.org/10.18535/jmscr/v8i8.33

\title{
Autologous whole blood versus corticosteroid local injection in treatment of plantar fasciitis
}

\author{
Authors \\ Imran Qayoom ${ }^{1}$, Tahir Shafi ${ }^{2}$, Mohd Rafeeq Wani ${ }^{3}$ \\ ${ }^{1,2,3}$ Postgraduate Scholar, Department of Orthopaedics, GMC Srinagar
}

\begin{abstract}
Plantar fasciitis is the most common cause of heel pain. Local injection modalities are among treatment options in patients with resistant pain.

Purpose: The aim of the present study was to evaluate the effect of local autologous whole blood compared with corticosteroid local injection in treatment of plantar fasciitis. In this randomized controlled study,

Method: 75 patients with chronic plantar fasciitis were recruited. Patients were allocated randomly into three treatment groups: local autologous blood, local corticosteroid injection, and control groups receiving no injection. Patients were assessed with visual analog scale (VAS) and plantar fasciitis pain/disability scale (PFPS) before treatment, as well as 4 and 12 weeks post therapy.

Result: Variables of pain and function improved significantly in both corticosteroid and autologous blood groups compared to control group. At 4 weeks following treatment, patients in corticosteroid group had significantly lower levels of pain than patients in autologous blood and control groups.

Keywords: Autologous whole blood. Corticosteriod. Plantar fasciitis.
\end{abstract}

\section{Introduction}

Plantar fasciitis (PF) is one of the common causes of heel pain characterized by pain at the calcaneal origin of the plantar fascia, exacerbated by weight bearing.

Conservative management is usually the initial treatment of $\mathrm{PF}^{1-4}$. Common conservative treatment modalities include modification in daily activities, use of orthoses, stretching exercises, and non-steroidal anti-inflammatory drugs

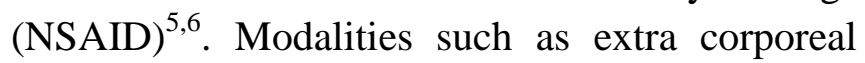
shockwave therapy, low-level laser therapy, fascial release, acupuncture, and needling are also used in conservative management. .,7,8,9,10 $^{-10}$

Chronic form of plantar fasciitis is disabling. ${ }^{11,12}$ It is believed that plantar fasciitis is a degenerative condition of the plantar fascia rather than an inflammation $^{[4]}$, which is characterized by micro tears of the plantar fascial ligament and intrinsic flexor muscles of the foot at their attachments on the calcaneus, resultant from repeated microtrauma due to overuse. ${ }^{4,13}$

Structural changes such as excessive foot pronations, forefoot varus, posterior tibialis weakness, and higher or lower arched foot are linked to developing PF. ${ }^{14,15}$

When conservative treatment fails in chronic PF, local injection of corticosteroid is among the treatment options available to patients with resistant pain ${ }^{[11]}$

Intralesional injection of autologous bloodderived products (ABDPs) such as platelet-rich 
plasma (PRP) or autologous whole blood (AWB) have gained attention as treatments for chronic musculoskletal problems such as knee osteoarthritis. $^{16,17}$

There are potent chemical factors in blood that can stimulate vascular in growth and fibroblast activity. ${ }^{18,19,20}$ Improvement in pain and function of patients with lateral epicondylitis ${ }^{21}$ and patellar tendinitis ${ }^{22}$ by blood product injections has been shown in previous studies. ${ }^{11,12}$ Blood product injections probably initiate an inflammatory reaction, with the potential to heal the tendinopathy. ${ }^{21-23}$ A number of studies have shown that intralesional injection of AWB provides comparable results to PRP for the treatment of tendinopathies. $^{24}$

Intralesional AWB injection was shown to improve pain in patients with chronic $\mathrm{PF}^{25}$, but it has not been as effective as corticosteroid injection in some studies.$^{26}$ In a systematic review, Tsikopoulos $\mathrm{K}$ and his colleagues compared the efficacy of AWB with corticosteroid injections on epicondylopathy and plantar fasciopathy. Corticosteroids were marginally superior to autologous whole blood in relieving pain on plantar fasciopathy at 2-6 weeks $^{26}$

\section{Aims and Objectives}

To compare the effect of intralesional injection of AWB and corticosteroid with conservative treatment in patients with chronic PF.

\section{Material and Methods}

Patients with signs and symptoms of chronic Plantar fasciitis who visited Department of Orthopaedics, GMC Srinagar from Sep 2018March 2020, were evaluated to enter this study.

\section{Inclusion Criteria}

Criteria for inclusion in the study were chronic clinically diagnosed PF based on history of pain beneath the heel for at least 8 weeks and site of tenderness and pain elicited by palpation of the medial calcaneal tubercle and or the proximal plantar fascia.)

\section{Exclusion Criteria}

Patients were excluded from the study if they had received any injection for PF within the previous 6 months, had history of previous surgery for plantar fasciitis, had active bilateral PF, had systemic inflammatory disease such as rheumatoid arthritis, or vascular insufficiency and neuropathy related heel pain. Other reasons for exclusion were if they were pregnant, or had history of vasovagal shock, hematologic, cardiovascular, renal or hepatic diseases, and infection near the injection site or local trauma.

\section{Ethical Considerations}

Informed consent was obtained from all patients. The process of the treatment was explained to the patients. The written consent form was signed or fingerprinted by the patients.

Patients were divided into three groups

\section{Group 1. (Autologous whole blood (AWB))}

The patients in this group received $1 \mathrm{ml}$ of autologous peripheral whole blood and $1 \mathrm{ml}$ of lidocaine $1 \%$ in single syringe.

\section{Group 2. (Corticosteroid)}

The patients in this group received $40 \mathrm{mg}$ methyl prednisolone and $1 \mathrm{~mL}$ lidocaine for a total of 3 $\mathrm{mL}$ volume in one syringe.

\section{Group 3. (Control group)}

Patients in this group did not receive any injection.

Conservative treatment was provided for these patients in form of education and daily stretching program.

\section{Injection technique}

Patients in group 1 and 2 were placed in prone position with knees extended in order to expose the plantar surface for treatment. The skin of the injection site was prepared with Betadine scrub and solution and sterile drape applied. In group 1, the autologous blood was injected in a single dose. The blood was drawn at the same session, mixed 
with anesthetic and injected immediately using a 22-gauge needle into the most tender point of plantar fascia at medial heel region ${ }^{27}$. The needle was inserted medially and directed laterally on the plantar surface just superior and anterior to the calcaneus $^{28}$. Group 2 received corticosteroid at the same site and under identical circumstances as group one.

\section{Patient's instructions}

All patients were asked to avoid running and other high impact activities for at least 2 weeks. Patients in groups 1 and 2 received the injection and were instructed to perform stretching exercises, while the control group received only the stretching exercises. During the 12 weeks of enrollment, all patients including control group were instructed to perform a daily stretching program shown to decrease pain associated with plantar fasciitis. The stretching technique required participants to cross their affected leg over the contralateral knee in a seated position, then pull back on the toes until they felt a stretch in the arch of their foot. Patients were instructed to repeat the stretch 10 times, with each stretch lasting for $10 \mathrm{~s}$. All patients were asked to complete the stretching program three times per day and to record their stretching frequency in a diary.

\section{Outcome Measures}

Before injections, all patients in three groups were asked to fill out the plantar fasciitis pain/disability scale (PFPS) questionnaire ${ }^{29}$ and were assessed by VAS ${ }^{34}$. At follow up intervals (at 4 and 12 weeks post treatment) the same measures were applied to evaluate pain and dysfunction related to PF.

\section{Functional Outcome Measures}

PFPS questionnaire evaluates patient's symptoms, satisfaction, disability, and disturbance in living activities $^{31-33}$. Pain intensity ranges from 0 (no pain) to 10 (agonizing pain). The validity and reliability of self-rating scales like the VAS have previously been well described ${ }^{34}$.

\section{Results}

75 patients were evaluated to enter this study. There were 25 patients in each group: corticosteroid, AWB, and control groups

\section{Outcome Measures}

All pain measures (VAS, and PFPS) improved significantly in corticosteroid and AWB groups at each of the three measurement intervals $(\mathrm{P}<$ 0.050 for all changes). Table 1,2 and 3 summarizes the mean VAS, and PFPS scores for the three groups at baseline, 4 and 12 weeks after treatment. As depicted in Table 1, 2 and 3 VAS and PFPS scores decreased in all groups at the 4 and 12 week follow-up evaluations. This improvement was not significant in the control group.

\begin{tabular}{|l|c|c|c|}
\hline Variable & $\begin{array}{c}\text { Autologous } \\
\text { Blood }\end{array}$ & Steroid & Control \\
\hline No of Patients & 25 & 25 & 25 \\
\hline Age (yrs) & $43.2 \pm 13.1$ & $46.8 \pm 14.3$ & $48.4 \pm 16.1$ \\
\hline Gender (F/M) & $17 / 8$ & $18 / 7$ & $16 / 9$ \\
\hline $\begin{array}{l}\text { Duration of } \\
\begin{array}{l}\text { Symptoms } \\
\text { (months) }\end{array}\end{array}$ & $6.3 \pm 3.2$ & $11.3 \pm 4.3$ & $8.4 \pm 4.1$ \\
\hline
\end{tabular}

Table 1 Baseline values

\begin{tabular}{|l|c|c|}
\hline Group & VAS & PFPS \\
\hline Blood & $8.5 \pm 2.2$ & $59 \pm 11.1$ \\
\hline Steroid & $7.1 \pm 1.2$ & $55.5 \pm 10.7$ \\
\hline Control & $7.3 \pm 1.7$ & $53 \pm 11.1$ \\
\hline
\end{tabular}

Table 2 At 4 wks

\begin{tabular}{|l|c|c|}
\hline Group & VAS & PFPS \\
\hline Blood & $6.2 \pm 1.3$ & $51.2 \pm 12.1$ \\
\hline Steroid & $4.4 \pm 2.3$ & $42.2 \pm 14.3$ \\
\hline Control & $5.3 \pm 2.2$ & $41.1 \pm 18.1$ \\
\hline
\end{tabular}

Table 3 At 12 wks

\begin{tabular}{|l|c|c|}
\hline Group & VAS & PFPS \\
\hline Blood & $3.9 \pm 1.3$ & $39.4 \pm 13.1$ \\
\hline Steroid & $3.1 \pm 2.3$ & $33.4 \pm 14.3$ \\
\hline Control & $6.1 \pm 3.2$ & $45.3 \pm 18.1$ \\
\hline
\end{tabular}

\section{Discussion}

Local corticosteroid injection led to an early sharp response at short term (4 week follow-up), and then a more gradual drop in average pain level, also improvement in function in 12 week, whereas AWB injection made steady gradual 
improvement. Patients in control group had also improvement in pain and function, which was not significant. The use of injections as a treatment modality for chronic or Refractory plantar fasciitis is common, and multiple types of injections have been proposed ${ }^{11,18,19}$.The efficacy of corticosteroid in treating chronic inflammation has been well demonstrated ${ }^{34-36}$. Intralesional injection of corticosteroid in chronic PF (defined as persistence of symptoms more than 8 weeks in spite of conservative care) has been shown to be effective ${ }^{37}$. Recently, the level 2 and 3 evidence shows that corticosteroids are more effective than placebo injections but probably less effective than platelet-rich plasma treatment.

In a review by Ang $\mathrm{TW}^{38}$, the effectiveness of corticosteroid injection in the treatment of PF was evaluated. All placebo-controlled RCTs showed a significant reduction in pain with the use of corticosteroid injections. However, it is evident from these studies that the effects of corticosteroid injections are usually short-term, lasting 4-12 weeks in duration.

The findings of the current study demonstrated an almost similar trend; the corticosteroid group showed an early sharp drop in VAS and then reached plateau in average pain levels as early as 4 weeks, and this was maintained for at least

3 months. AWB contains platelets with strong growth factors that may help the healing process of chronic injuries. Known platelet growth factors stimulate the healing process and lead to partial modification of the damaged tissue $\mathrm{e}^{24-26,29}$.

AWB and PRP induce angiogenesis, increase growth factor expression and cell proliferation ${ }^{22-}$ ${ }^{24}$. In a study by Vahdatpour and his colleagues, intralesional injection of PRP and AWB had similar effectiveness for the treatment of chronic $\mathrm{PF}$ in short term ${ }^{31}$. In a meta-analysis by Hsiao MY et al., the effectiveness of ABPs, shockwave therapy, and corticosteroids for treatment of PF were compared. In conclusion, they reported that ABPs were favored over corticosteroids regarding VAS reduction at 3 months ${ }^{37}$. Shockwave therapy and ABPs had similar effectiveness for providing pain relief at 6 months, and were better than corticosteroids at that time ${ }^{37}$.

PRP as a blood product richer in platelets than AWB has been shown to be more effective and durable than cortisone injection for the treatment of chronic recalcitrant cases of PF in long-term follow-up studies.

\section{Conclusion}

Based on the findings of the present study, the effect of local AWB injection in chronic PF was superior to conservative treatment and comparable to corticosteroid injection, while its efficacy lasted longer. However, improvement was also noticed in the control group to a lesser extent. Hence, noninvasive and conservative treatment would be the appropriate first-line choice for this condition. Corticosteroid or AWB injection have comparable efficacy regarding pain and function improvement and can be used as second-line treatment alternatives. Regarding cost analysis of using injection versus conservative treatments in chronic $\mathrm{PF}$, despite the cost of corticosteroid or AWB injection being slightly higher than conservative treatment, they can be considered a readily available, well-tolerated, and safe choice of therapy in chronic PF. Corticosteroid injections have been reported to carry a risk of complications such as fat pad atrophy, pain, bleeding, bruising, infection, contact allergic dermatitis due to the preservative, skin atrophy, osteomyelitis of the calcaneus, and rupture of the plantar fascia. Higher doses of corticosteroids may be contraindicated for certain patients with comorbidities such as uncontrolled diabetes mellitus or severe hypertension. As such, there is a clinically recommended limit for corticosteroid doses per person over time in order to avoid these potential side effects, whereas AWB injection may not have the same limitation. Although we did not observe any complications related to steroid injection, AWB injection seems to be safer in this regard. 


\section{References}

1. Buchbinder R (2004) Clinical practice. Plantar fasciitis. N Engl J Med 350:21592166.

2. Grieve R, Palmer S (2016) Physiotherapy for plantar fasciitis: a UK-wide survey of current practice. Physiotherapy. doi:10.1016/j. physio.2016.02.002

3. Thomas JL, Christensen JC, Kravitz SR, Mendicino RW, Schuberth JM, Vanore JV et al (2010) The diagnosis and treatment of heel pain: a clinical practice guidelinerevision 2010. J Foot Ankle Surg 49(3 Suppl):S1-19.

4. Ribeiro AP, João SM, Dinato RC, Tessutti VD (2015) Sacco IC.Dynamic patterns of forces and loading rate in runners with unilateral PlantarFasciitis: a crosssectional study. PLoS One 10(9): e0136971.

5. Lim AT, How CH, Tan B (2016) Management of plantar fasciitis in the outpatient setting. J Orthop Sports Phys Ther 6:1-101.

6. Yu H1, Randhawa K, Côté P, Optima Collaboration (2016) The effectiveness of physical agents for lower-limb soft tissue injuries: a systematic review. J Orthop Sports Phys Ther 6:1-101

7. Eslamian F, Shakouri SK, Jahanjoo F, Hajialiloo M, Notghi F (2016) Extra corporeal shock wave therapy versus local corticosteroid injection in the treatment of chronic plantar fasciitis, a single blinded randomized clinical trial. Pain Med 17(9):1722-1731.

8. Macias DM, Coughlin MJ, Zang $\mathrm{K}$, Stevens FR, Jastifer JR, Doty JF (2015) Low-level laser therapy at $635 \mathrm{~nm}$ for treatment of chronic plantar fasciitis: a placebo-controlled, randomized study. J Foot Ankle Surg 54(5):768-772.

9. Piper S, Shearer HM, Côté P et al (2016) The effectiveness of softtissue therapy for themanagement of musculoskeletal disorders and injuries of the upper and lower extremities: a systematic review by the Ontario Protocol for Traffic Injury management (OPTIMa) collaboration. Man Ther 21:18-34.

10. Cox J, Varatharajan S, Côté P (2016) J. Effectiveness of acupuncture therapies to manage musculoskeletal disorders of the extremities: a systematic review. Orthop Sports Phys Ther 46(6):409-429.

11. Akşahin E1, Doğruyol D, HY Y, Hapa O, Doğan O, Celebi L, Biçimoğlu A et al (2012) Arch Orthop Trauma Surg 132(6):781- 785. doi:10.1007/s00402-012 1488-5.

12. Tong KB, Furia J (2010) Economic burden of plantar fasciitis treatment I the United States. Am J Orthop (Belle Mead NJ) 39(5): 227-231.

13. Gardner B (2015) Plantar Fasciitis. Conn Med 79(3):159-160.

14. La Porta GA, La Fata PC et al (2005) Clin Podiatr Med Surg 22(1): 1-9

15. Bolgla LA, Malone TR (2004) Plantar fasciitis and the windlass mechanism: a biomechanical link to clinicalpractice. J Athl Train 39(1):77-82

16. RayeganiSM, Raeissadat SA, TaheriMS, BabaeeM, BahramiMH, Eliaspour D, Ghorbani E (2014) Does intra articular platelet rich plasma injection improve function, pain and quality of life in patients with osteoarthritis of the knee? A randomized clinical trial. Orthop Rev (Pavia) 6:5405

17. Raeissadat SA, Rayegani SM, Hassanabadi H, Fathi M, Ghorbani E, BabaeeM, Azma K (2015) Knee osteoarthritis injection choices: plateletrich plasma (PRP) versus hyaluronic acid (a one-year randomized clinical trial). Clin Med Insights Arthritis Musculoskelet Disord 8:1-8

18. Ragab EM, Othman AM (2012) Platelets rich plasma for treatment of chronic 
plantar fasciitis. Arch Orthop Trauma Surg 132(8):1065- 1070.

19. O'Malley MJ, Vosseller JT, Gu Y (2013) Successful use of platelet rich plasma for chronic plantar fasciitis. HSS J 9(2):129133.

20. Martinelli N, Marinozzi A, Carnì S, Trovato U, Bianchi A, Denaro V (2013) Platelet-rich plasma injections for chronic plantar fasciitis. Int Orthop 37(5):839-842

21. Raeissadat SA, Rayegani SM, Hassanabadi H, Rahimi R, Sedighipour L, Rostami K (2014) Is Platelet-rich plasma superior to whole blood in the management of chronic tennis elbow: one year randomized clinical trial. BMC Sports Sci Med Rehabil 18:6- 12.

22. Liddle AD, Rodríguez-Merchán EC (2015) Platelet-rich plasma in the treatment of patellar tendinopathy: a systematic review. Am J Sports Med 43(10):2583-2590.

23. Balasubaramin U, Dissanayake R, Annabell L (2015) Efficacy of platelet-rich plasma injections in pain associated with chronic tendinopathy: a systematic review. Phys Sportsmed 43(3):253-261

24. Sandrey MA (2014) Autologous growth factor a injections in chronic tendinopathy. J Athl Train 49:428-430.

25. Chew KT, Leong D, Lin CY, LimKK, Tan B (2013) Comparison of autologous conditioned plasma injection, extracorporeal shockwave therapy, and conventional treatment for plantar fasciitis: a randomized trial. PM R 5(12):10351043.

26. Tsikopoulos K, Tsikopoulos A, Natsis K (2016) Autologous whole blood or corticosteroid injections for the treatment of epicondylopathy and plantar fasciopathy? A systematic review and meta-analysis of randomized controlled trials. Phys Ther Sport. doi: 10.1016/j.ptsp.2016.02.002
27. Babak Vahdatpour B, Kianimehr L, Ahrar MH (2016) Autologous platelet-rich plasma compared with whole blood for the treatment of chronic plantar fasciitis; a comparative clinical trial. Adv Biomed Res 5:84.

28. Lento P, Ihm J, Kennedy DJ, Visco CJ (2011) PERIPHERAL JOINT AND SOFT TISSUE INJECTION TECHNIQUES. In: Braddom RL (ed) Physical Medicine \& Rehabilitation, 4th edn. Elseviers, Philadelphia, pp 517-540.

29. Budiman-Mak E, Conrad KJ, Mazza J, Stuck RM (2013) A review of the foot function index and the foot function indexrevised. J Foot Ankle Res 6(1):5.

30. Park G et al (2011) Reliability and usefulness of the pressure pain threshold measurement in patients with myofascial pain. Ann Rehabil Med 35(3):412-417.

31. Chen CM, Chen JS, Tsai WC, Hsu HC, Chen KH, Lin CH (2013) Effectiveness of device-assisted ultrasound-guided steroid injection for treating plantar fasciitis. Am J Phys Med Rehabil 92(7):597-605.

32. Saban B, Masharawi Y (2016) Pain threshold tests in patients with heel pain syndrome. Foot Ankle Int 37(7):730-736.

33. Foster ZJ, Voss TT, Hatch J, Frimodig A (2015) Corticosteroid injections for common musculoskeletal conditions. Am Fam Physician 92(8):694-699.

34. Karls SL, Snyder KR, Neibert P (2016) Effectiveness of corticosteroid injections in the treatment of plantar fasciitis. J Sport Rehabil 25(2):202-207.

35. Mahindra P, Yamin M, Selhi HS, Singla S, Soni A (2016) Chronic plantar fasciitis: effect of platelet-rich plasma, corticosteroid, and placebo. Orthopedics 39(2):e285-e289.

36. Say F, Gürler D, İnkaya E, Bülbül M (2014) Comparison of platelet-rich plasma and steroid injection in the treatment of 
plantar fasciitis. Acta Orthop Traumatol Turc 48(6):667-672.

37. Hsiao MY, Hung CY, Chang KV, Chien KL, Tu YK, Wang TG (2015) Comparative effectiveness of autologous blood-derived products, shock-wave therapy and corticosteroids for treatment of plantar fasciitis: a network metaanalysis. Rheumatology (Oxford) 54:1735-1743.

38. Ang TW (2015) The effectiveness of corticosteroid injection in the treatment of plantar fasciitis. Singap Med J 56:423432. 